\title{
Fe de errores a «Resistencia compresiva de dientes con conductos amplios restaurados con dos técnicas»
}

\section{Erratum to «Compressive resistance of teeth with large conducts restored with two techniques»}

\footnotetext{
Johana Sánchez ${ }^{1}$, Andra Jiménez ${ }^{1}$, Jerónimo Gale ${ }^{1}$, Adalgasia Alcocer $^{1,2^{*}}$, Erick Meyer ${ }^{1}$, Alfredo Vargas ${ }^{1,2}$

1 Fundación Universidad San Martín, Colombia. 2 Universidad Metropolitana, Colombia.

* Correspondencia autor: Adalgisa Alcocer Calle 76 \# 42 -78 Barranquilla- Colombia. | Telefono +573016506110 | Email: aalcocer@unimetro.edu.co Trabajo recibido el 24/07/2017. Aprobado para su publicación el 22/10/2017

En el artículo «Resistencia compresiva de dientes con conductos amplios restaurados con dos técnicas» (Rev. Clin. Periodoncia Implantol. Rehabil. Oral Vol. 11(1); 20-23, 2018.) de Adalgisa Alcocer se ha detectado un error de transcripción en el enunciamiento de los autores. Se corrige el nombre de Adalgisa.

Johana Sánchez ${ }^{1}$, Andra Jiménez ${ }^{1}$, Jerónimo Gale ${ }^{1}$, Adalgisa Alcocer ${ }^{1,2^{*}}$, Erick Meyer $^{1}$, Alfredo Vargas ${ }^{1,2}$
}

Véase contenido relacionado en DOI: 10.4067/S0719-01072018000100020 